\title{
Aislamiento bacteriológico y caracterización de lesiones histopatológicas en tetra bleeding heart (Hyphessobrycon erythrostigma) de la cuenca amazónica peruana
}

\author{
BACTERIOLOGICAL ISOLATION AND CHARACTERIZATION OF HISTOPATHOLOGICAL LESIONS IN \\ tetra bleeding heart (Hyphessobrycon erythrostigma) of the Peruvian \\ Amazon basin
}

Adhemir Valera A. ${ }^{1,3}$, Jessica Jurado P. ${ }^{1}$, Alberto Manchego S. ${ }^{2}$, Nieves Sandoval C. ${ }^{1}$

\section{Resumen}

El objetivo del presente estudio fue determinar la presencia de agentes bacterianos y caracterizar las lesiones histopatológicas en tejidos del pez ornamental 'tetra bleeding heart' (Hyphessobrycon erytrhostigma) procedentes de un acuario comercial de la ciudad de Iquitos, Perú. Para el estudio microbiológico se utilizaron 60 peces, tomándose muestras de bazo y riñón. El aislamiento se hizo en agar MacConkey, agar Tripticasa de Soya, agar selectivo para Pseudomonas-Aeromonas (GSP) y agar Cytophaga. La identificación de los géneros bacterianos se hizo mediante la coloración Gram y pruebas bioquímicas. Para el estudio histopatológico se utilizaron otros 60 peces, evaluándose los tejidos de piel, ojo, branquias, estómago, intestino, hígado, bazo, músculo, riñón y peritoneo. Se aislaron siete géneros bacterianos: Pseudomonas, Aeromonas, Lactobacillus, Bacillus, Flavobacterium, Staphylocccus y Escherichia. En los estudios histopatológicos, se observó en las branquias la presencia de esporas de Mixosporidium sp, hiperplasia y fusión de lamelas; en hígado y peritoneo se hallaron granulomas parasitarios y bacterianos; en músculo, riñón y bazo se encontraron granulomas bacterianos; y en el estómago e intestino se observó hiperplasia de las células epiteliales, entre otras lesiones. El 52.3\% (22/42) de los granulomas bacterianos fueron positivos a la tinción de Ziehl Neelsen, donde se evidenció bacterias bacilares largas acidorresistentes. No se observaron lesiones en los ojos.

Palabras clave: Hyphessobrycon erythrostigma; estudio microbiológico; estudio histopatológico

${ }^{1}$ Laboratorio de Histología, Embriología y Patología Veterinaria, ${ }^{2}$ Laboratorio de Microbiología y Parasitología Veterinaria, Facultad de Medicina Veterinaria, Universidad Nacional Mayor de San Marcos, Lima, Perú

${ }^{3}$ E-mail: nieves.sandovalchaupe@gmail.com

Recibido: 6 de marzo de 2017

Aceptado para publicación: 15 de octubre de 2017 
The aim of this study was to determine the presence of bacterial agents and to characterize the histopathological lesions in ornamental tetra bleeding heart (Hyphessobrycon erytrhostigma) fish from a commercial aquarium in the city of Iquitos, Peru. For the microbiological study 60 fish were used, samples were taken from spleen and kidney. Isolation was done on MacConkey agar, Trypticase Soy agar, Pseudomonas Aeromonas selective agar (GSP) and Cytophaga agar and the genus identification was done by Gram staining and biochemical tests. Another 60 fish were used for the histopathological study where the skin, eye, gills, stomach, intestine, liver, spleen, muscle, kidney and peritoneum tissues were analyzed. Seven bacterial genera were isolated: Pseudomonas, Aeromonas, Lactobacillus, Bacillus, Flavobacterium, Staphylocccus and Escherichia. Spores of Mixosporidium sp, hyperplasia and lamella fusion were observed in gills. In the liver and peritoneum, parasitic and bacterial granulomas were found. In muscle, kidney and spleen, bacterial granulomas were found, and in stomach and intestine epithelial cell hyperplasia were found, among other lesions. Results showed that 52.3\% (22/42) of the bacterial granulomas were positive for Ziehl Neelsen staining, which showed acid-fast bacilli bacteria. No lesions were found in the eyes.

Key words: Hyphessobrycon erythrostigma; microbiological study; histopathological study

\section{INTRODUCCIÓN}

Un estudio hecho en el Perú en 2006 reveló que 100000 personas se beneficiaban con la extracción de peces ornamentales (FAO, 2010). La explotación y el comercio de peces ornamentales se ha convertido en una actividad económicamente importante, dado el incremento en la demanda nacional e internacional, exportándose a los Estados Unidos de América, Europa y Asia (Ruiz, 2005; FAO, 2010).

La salud de los peces puede afectarse por enfermedades causadas por diversos agentes patógenos, pudiendo llegar a ocasionarles la muerte (Roberts, 2001). Muchas de estas enfermedades son producidas por bacterias, las cuales ingresan al medio acuático ante un mal manejo sanitario, mientras que otras habitan como flora normal del pez o del agua. Sin embargo, en casos de estrés se tiene una respuesta inmune ineficiente en los peces, , que es aprovechada por estas bacterias para provocar infecciones (Chuquipiondo,
2014). Asimismo, diversos agentes patógenos que infectan peces de acuario tienen la capacidad de afectar al humano por lo que tienen una implicancia relevante en salud pública (CFSPH, 2007).

Los 'tetra bleeding heart' (Hyphessobrycon erythrostigma), conocidos también como tetra corazón sangrante o tetra de mancha roja, son parte de los peces con mayor demanda a nivel internacional (Araujo y Bances, 2009). En peces ornamentales de Rio Negro, Brasil, incluyendo al 'tetra bleeding heart' se han aislado bacterias de los géneros Staphylococcus, Nocardia, Acinetobacter y Lactococcus, bacterias potencialmente patógenas y que proliferan en condiciones de estrés (Carvalho et al., 2015). Es poco lo que se conoce del estado sanitario de esta especie en el Perú, de allí que se requiere estudiar los agentes bacterianos que causan lesiones en los tejidos. En el presente trabajo se realiza el estudio microbiológico e histopatológico de $H$. erythrostigma provenientes de la Amazonía del Perú. 


\section{Materiales y Métodos}

\section{Tipo y Lugar de Estudio}

El estudio fue de tipo observacional transversal descriptivo y se llevó a cabo en 2015. Los peces en estudio provinieron de un centro de exportación de peces ornamentales amazónicos ubicado en la ciudad de Iquitos, Loreto, Perú. Los peces son capturados en los ríos de la selva peruana y agrupados, según la especie, en acuarios donde reciben el cuidado necesario para su alimentación y mantenimiento de la calidad del agua.

\section{Tamaño de Muestra}

El tamaño de muestra se basó en una frecuencia de $50 \%$ de casos esperados, como escenario conservador, un nivel de confianza del $95 \%$ y un error aceptado del $10 \%$. Con esta base, se seleccionaron 120 peces 'tetra bleeding heart' (H. erythrostigma). Debido al pequeño tamaño de los peces $(6$ cm de longitud) y de sus órganos (bazo de 2 $\mathrm{mm}$ de diámetro, riñón de $3 \times 2 \mathrm{~mm}$ ), la mitad de los peces se empleó en el estudio microbiológico y la otra mitad en el estudio histopatológico,

\section{Material Biológico}

Los peces se encontraban en aparente buen estado de salud y recibían alimento peletizado. Fueron trasladados 140 peces al Laboratorio de Ictiopatología de la Facultad de Medicina Veterinaria (FMV) de la Universidad Nacional Mayor de San Marcos, en Lima, en bolsas con agua de su propio acuario y con suficiente oxígeno. Se les mantuvo en ayunas por $12 \mathrm{~h}$ para vaciar su tubo digestivo, con la finalidad que el agua de transporte permanezca limpia. El tiempo del transporte fue de tres horas.

A la llegada, los peces fueron trasladados a acuarios, pero no fueron puestos directamente con el agua de estos recipientes para evitar diferencias en cuanto a temperatura y oxígeno disuelto. Se hizo un cambio gradual durante $24 \mathrm{~h}$. Los peces recibieron alimento peletizado hasta realizar el proceso experimental, donde se seleccionaron 120 peces.

\section{Necropsia}

Los peces fueron anestesiados mediante adición al agua de benzocaína $1 \mathrm{~g}$ por cada 201 (Ross L y Ross B, 2008) y sacrificados mediante corte medular con hoja de bisturí entre el cerebro y la medula espinal (Roberts y Sheperd, 1980; Rosenthal, 2013). La necropsia se realizó según los procedimientos de rutina (Reimschuessel et al., 1988).

\section{Estudio Microbiológico}

Con ayuda de una lupa, se realizaron punciones en el riñón y el bazo en los 60 peces, utilizando un ansa estéril de punta para el aislamiento de las bacterias.

Las muestras fueron sembradas en medio agar Tripticasa de Soya (TSA) a $30^{\circ} \mathrm{C}$ por $24 \mathrm{~h}$, Agar Cytophaga a $30^{\circ} \mathrm{C}$ por $96 \mathrm{~h}$, agar específico el aislamiento de bacterias del género Flavobacterium, Agar GSP a $30{ }^{\circ} \mathrm{C}$ por $96 \mathrm{~h}$, agar específico para el aislamiento de Aeromonas sp y Pseudomonas sp, y Agar MacConkey a $30^{\circ} \mathrm{C}$ por $24 \mathrm{~h}$ para el crecimiento de bacterias gramnegativas. Para la identificación bacteriana se utilizó el diagrama de identificación propuesto por Orvay (1993), así como el Manual de Determinación Bacteriológica de Bergey's (Hoelt et al., 2000). Los primeros aislados fueron conservados en refrigeración $\left(8^{\circ} \mathrm{C}\right)$ en espera del crecimiento de todas las muestras. Para la identificación y caracterización de las colonias se utilizó la coloración Gram y pruebas bioquímicas como: oxidasa, catalasa, Medio LIA, Agar Simmons Citrato, Medio TSI, Rojo de Metilo-Vogues Proskauer, Medio SIM y la prueba de óxido-reducción. 


\section{Estudio Histopatológico}

Luego del sacrificio, se separó la cabeza, cola y aletas del resto del cuerpo, y fueron colocados en un frasco rotulado que contenía formol tamponado al $10 \%$ hasta su procesamiento. Se realizó la tinción convencional de hematoxilina y eosina a todas las muestras, y la tinción Ziehl-Neelsen en las muestras que presentaban granulomas con sospecha de ser causadas por Mycobacterium sp. Las láminas histológicas fueron observadas con un microscopio óptico de luz con aumentos de 10X, 40X, 100X para determinar lesiones patológicas en bazo, riñón, hígado, estómago, intestino delgado, peritoneo, ojo, piel, músculo esquelético y branquias. Los hallazgos fueron categorizados según el grado de afección (normal, escaso, leve, moderado y severo) y tipo de trastorno (de crecimiento, parasitario, circulatorio, inflamatoria y degenerativo) propuestos por Reimshuessel et al. (1992).

\section{Análisis de Datos}

Se realizaron estimaciones de frecuencias de los géneros bacterianos aislados y de las lesiones histopatológicas encontradas, según Bland y Alman (1986).

\section{Consideraciones Éticas}

En el estudio se contemplaron las normas éticas para la investigación señaladas por el Comité de Ética y Bienestar Animal de la Facultad de Medicina Veterinaria de la Universidad Nacional Mayor de San Marcos.

\section{Resultados}

En el cultivo microbiológico de las muestras de bazo y riñón se identificaron siete géneros bacterianos: Flavobacterium (16/60; $26.7 \%)$, Bacillus (13/60; 21.6\%), Staphylococcus (11/60; 28.3\%), Aeromona (6/60;10\%), Pseudomona (3/60;5\%), Lactobacillus $(1 / 60 ; 1.7 \%)$, Plesiomona $(1 / 60 ; 1.7 \%)$ y Escherichia $(9 / 60 ; 15 \%)$.
En el estudio histopatológico del bazo solo se observaron granulomas bacterianos (Figura 1A en el 13.3\% (8/60) de las muestras, con un grado de afección escaso y leve.

En la piel se encontró necrosis epitelial $(3.3 \% ; 2 / 60)$ e infiltración de células inflamatorias en el $20 \%$ de los casos (12/60) (Figura 1B).

En el músculo esquelético se observaron pocos quistes de Microsporidium sp (5\%; 3/60) (Figura 1C), granulomas bacterianos $(5 \% ; 3 / 60)$ (Figura 1D), infiltración de células inflamatorias $(73.3 \%$; 44/60) y necrosis de las fibras musculares (95\%; 57/60) (Figura $1 \mathrm{E}$ ), siendo estos dos últimos hallazgos de grado escaso y leve.

En el estómago se observó hiperplasia de las células epiteliales $(85 \% ; 51 / 60)$ y atrofia de las células epiteliales $(10 \%$; 6/60) (Figura 2A), ambas en grado leve. Además, se encontraron lesiones degenerativas como desprendimiento de las células epiteliales $(20 \% ; 12 / 60)$ y necrosis del epitelio estomacal (43.3\%; 26/60) (Figura 2B), mayormente de grado escaso. En el peritoneo solo se observaron granulomas bacterianos $(31.6 \%$; $19 / 60)$, granulomas de tipo parasitario $(36.6 \%$, 22/60) e infiltración de células inflamatorias $(16.6 \% ; 10 / 60)$ (Figuras 2C, D).

En el hígado, las lesiones más frecuentes fueron la degeneración hidrópica (88.3\%) y la degeneración grasa (43.3\%) (Figura 3A) en grados de afección severos. Además, se encontraron granulomas parasitarios (33.3\%) (Figura 2F) (ver Cuadro 2).

En las branquias, todas las muestras presentaron hiperplasia del epitelio, fusión de lamelas secundarias (Figura 3A) y esporas de Mixosporidium sp (Figura 3B). Asimismo, se encontró infiltración de células inflamatorias en el $63.3 \%$ de las muestras (Figura 3B) (ver Cuadro 1). En el riñón, los túbulos renales presentaban degeneración hidrópica (93.3\%) y edema peritubular (61.6\%) (Figura 3C), además de granulomas bacterianos (13.3\%) (Figura 3D (ver Cuadro 4). 


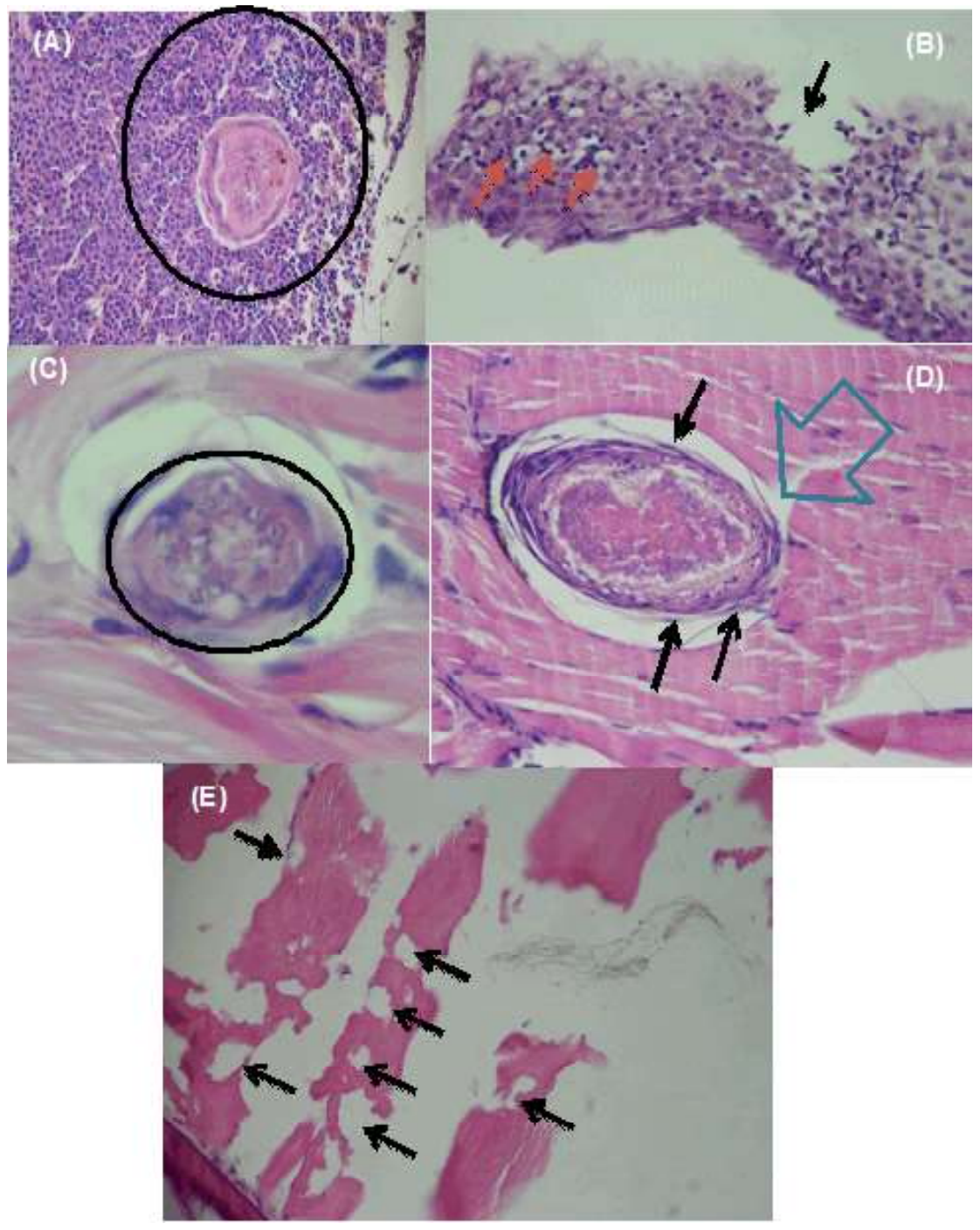

Figura 1. Cortes histológicos de órganos de 'tetra bleeding heart' (Hyphessobrycon erytrhostigma). A. Granuloma en el tejido esplénico (círculo). B. Necrosis del tejido epitelial (flecha negra) e infiltración de células inflamatorias de tipo linfocitaria (flechas rojas). C Quiste con esporas de microsporidios (círculo) en músculo. D. Granuloma bacteriano (flecha verde) en tejido muscular, nótese alrededor los fibroblastos (flechas negras). E. Áreas de necrosis en las fibras musculares (flechas negras). F. Necrosis (flechas negras) y desprendimiento de las células epiteliales (flechas rojas). H-E. 400X

En la histología del intestino, el 78.3\% de las muestras presentaron hiperplasia de los enterocitos (Figura $3 \mathrm{E}$ ) y el $41.6 \%$ presentaba necrosis de los enterocitos (Figura 3F), desde grado escaso a moderado (Cuadro 1). Por otro lado, no se encontraron lesiones histopatológicas en ojos.
En 42 muestras de órganos teñidas con $\mathrm{H}-\mathrm{E}$ se observaron granulomas bacterianos. Estos fueron sometidos a tinción de Ziehl Neelsen encontrando 22 muestras positivas $(52.3 \%, 22 / 42)$, correspondiendo al hígado (3/ 4), riñón (4/8), músculo esquelético (1/3), bazo $(2 / 8)$ y peritoneo (12/19). En las láminas posi- 


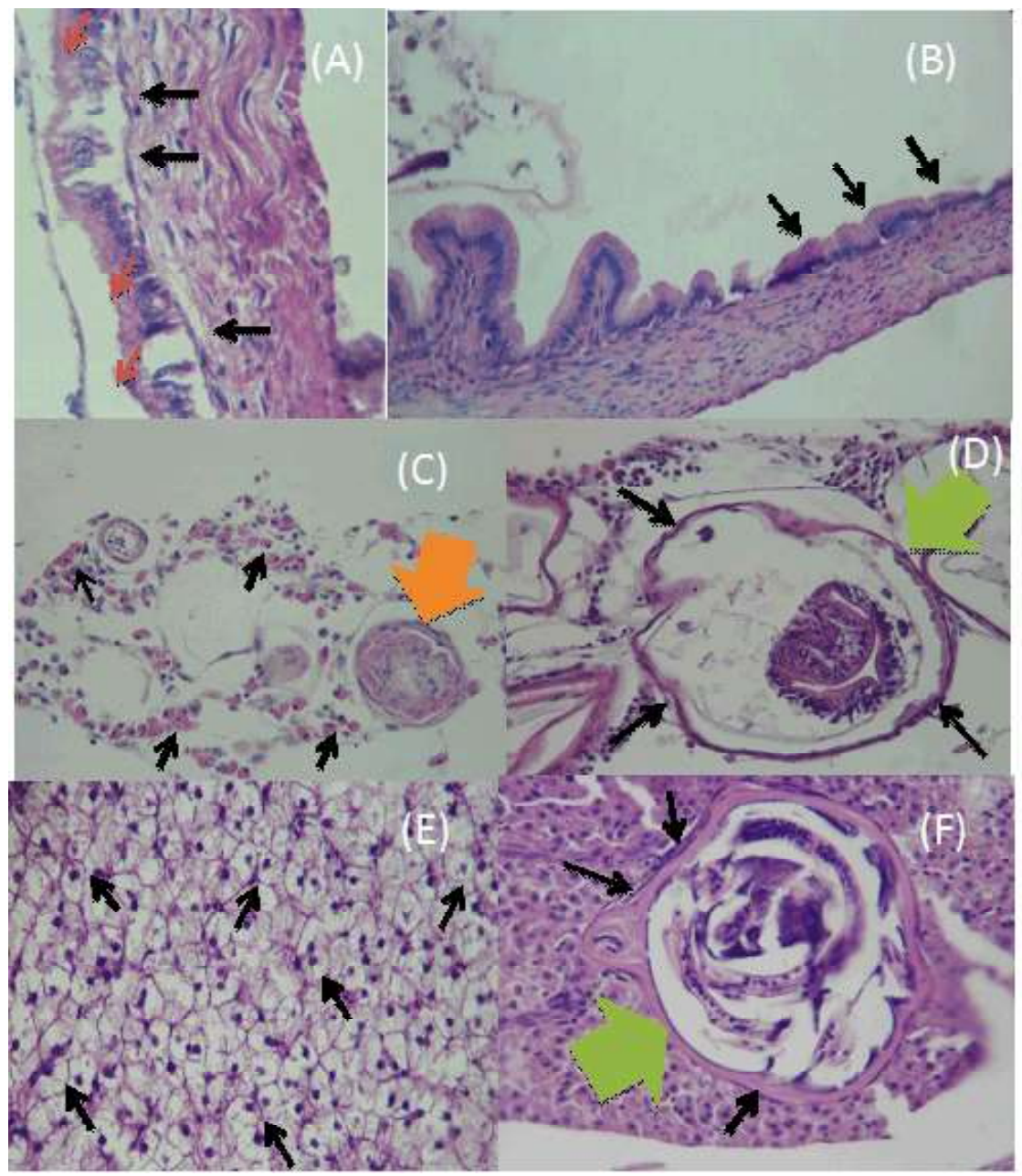

Figura 2. Cortes histológicos del estómago, peritoneo e hígado de 'tetra bleeding heart' (Hyphessobrycon erytrhostigma). A. Necrosis (flechas negras) y desprendimiento de las células epiteliales (flechas rojas) del estómago. B. Áreas con atrofia en la mucosa gástrica (flechas negras). C. Granuloma bacteriano (flecha naranja) e infiltración de células inflamatorias (flechas negras) en peritoneo. D. Granuloma parasitario (flecha verde), fibroblastos (flechas negras) en peritoneo. E. Degeneración grasa en hígado. Se puede observar a los hepatocitos redondos y con su núcleo excéntrico (flechas negras). F. Granuloma parasitario en hígado (flecha verde), fibroblastos (flechas negras). H-E. 400X

tivas se evidenciaron bacterias bacilares ácido resistentes en el interior de los granu-lomas (Figura 4).

Lesiones histológicas como granulomas que contienen bacilos acidorresistentes fueron pruebas sólidas de la presencia de bacterias del género Mycobacterium en peces (Center for Food Security and Public Health, 2006).

\section{Discusión}

Los resultados indican una frecuencia elevada de peces infectados con siete géneros bacterianos potencialmente patógenos. Esto es similar a los valores hallados por Palacios et al. (2015) en tetra neón 


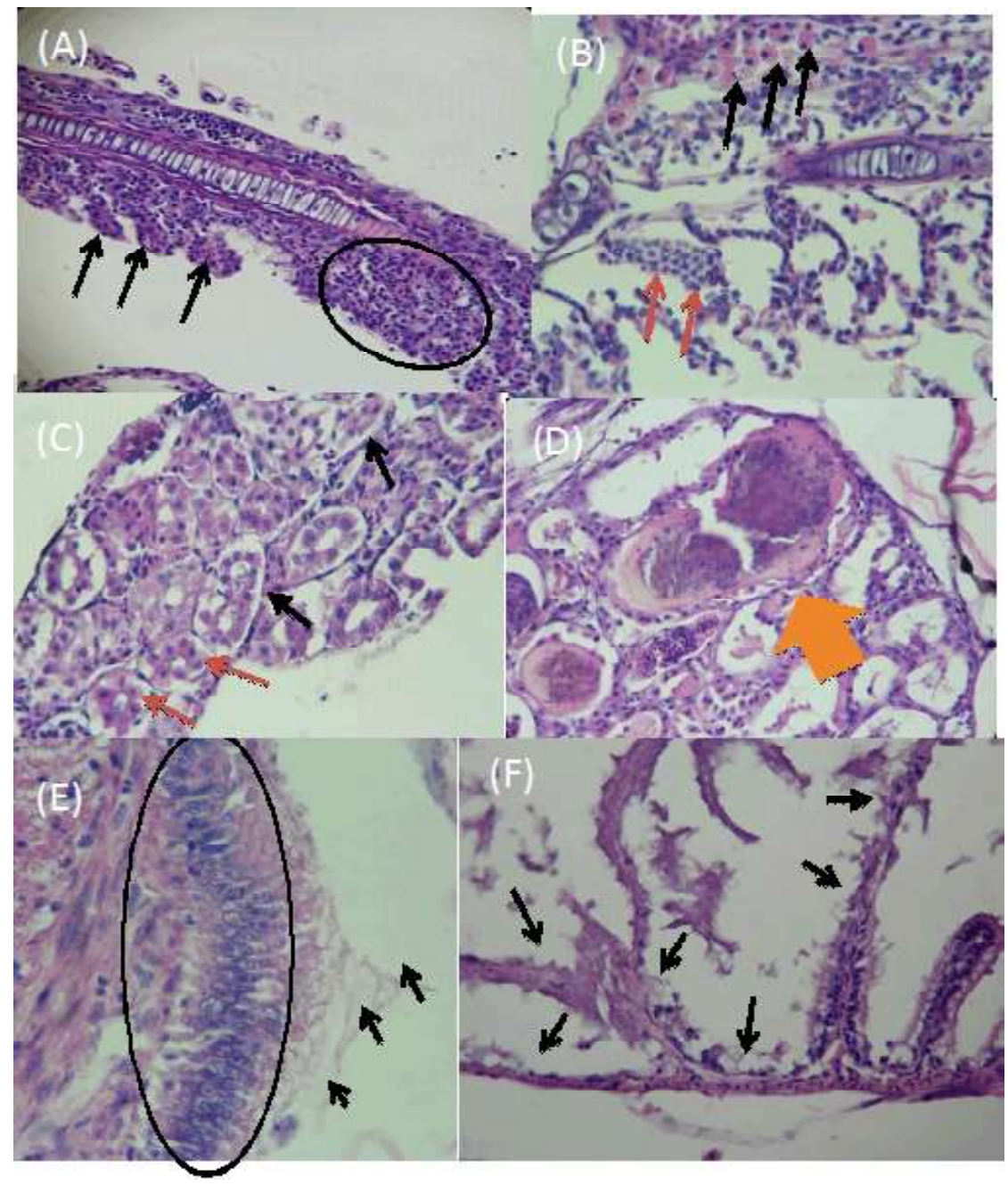

Figura 3. Cortes histológicos de branquias, riñón e intestino de 'tetra bleeding heart' (Hyphessobrycon erytrhostigma). A. Hiperplasia de lamelas (flechas negras), fusión de lamelas (círculo negro) en branquias. B. Células inflamatorias (flechas negras), esporas de Mixosporidium sp (flechas rojas) en tejido branquial. C. Edema peritubular (flechas negras) y degeneración hidrópica de las células renales que conforman el túbulo renal (flechas rojas). D. Granulomas bacterianos (flechas rojas) en tejido renal. E. Hiperplasia de los enterocitos (Círculo negro), desprendimiento de las células epiteliales de la mucosa intestinal (flechas negras). F. Áreas de necrosis en el epitelio intestinal (flechas negras). H-E. 400X

(Paracheirodon innesi), donde se ha encontrado bacterias de los géneros Flavobacterium, Staphylococcus, Pseudomonas y Bacillus; indicando que ambas especies de peces son susceptibles a infectarse con bacterias de los mismos géneros.
Los peces del estudio fueron considerados como clínicamente sanos; sin embargo, el $27.1 \%$ se encontraba infectado con Flavobacterium sp. Se ha demostrado en peces que las respuestas inmunes innatas y adquiridas que se activan frente a patógenos 
bacterianos permiten que las infecciones subclínicas se tornen en clínicas cuando los peces son sometidos a condiciones inmunosupresoras como el estrés de captura y de cautiverio en acuarios (Ellis, 2001).

Las lesiones de hiperplasia en branquias se consideran como respuestas adaptativas frente a afecciones tisulares, pero cuando la hiperplasia no es lo suficientemente rápida para proteger a las lamelas ocurre la fusión lamelar (Ramírez et al., 2009). Estas lesiones pueden ser causadas por agentes bacterianos, parasitarios e incluso por una mala calidad del agua (Noga, 2000). Según Domitrovic (1998), estas lesiones también pueden ser causadas por Mixosporidium sp, lo cual concuerda con este estudio donde se observó la presencia de estas esporas en todas las muestras. Similar conclusión fue dada por Iregui et al. (1999) en cachama blanca (Piaractus brachypomus) quienes reportan una severa atrofia de las lamelas ante la presencia de estos parásitos.

Las lesiones en piel fueron poco frecuentes (infiltración de células inflamatorias, necrosis e hiperplasia de células epiteliales). Estos hallazgos están relacionados a procesos inflamatorios asociados a bacterias de los géneros Escherichia, Pseudomonas y Aeromonas entre otros. Escherichia spp puede causar daño a nivel intestinal o producir lesiones en las branquias y en piel, como ha sido observado en peces ornamentales tropicales Poecilia sp y Carassius sp (Austin B y Austin D, 2007). Este tipo de lesiones son similares a las encontradas en tilapia nilótica (Oreochromis niloticus) infectadas naturalmente por Pseudomona fluorescences y Aeromona hydrophila (Mohamed E y Mohamed M, 2008). Es importante señalar que bacterias del género Aeromonas son parte de la microflora intestinal normal de peces (Trust et al., 1974) y que cuadros de enfermedad por Pseudomonas ocurre ante una baja de la inmunidad (Salcido, 1998) como puede ocurrir ante el estrés por el transporte de los peces.
El 5\% de muestras de músculo esquelético afectadas por quistes de Microsporidium sp y $5 \%$ por granulomas bacterianos difiere del reporte de Palacios et al. (2015), quienes encontraron quistes de Microsporidium $\mathrm{sp}$ en la mayoría de individuos tetra neón (P. innesi). Por otro lado, Ferguson (2006) sostiene que la mayoría de los microsporidios con estadios inmaduros parecen producir una leve a nula respuesta inflamatoria y, generalmente, son encontrados como hallazgos incidentales en el trabajo de rutina diagnóstica. La necrosis muscular observada en este estudio pudo estar relacionada con agentes bacterianos o parasitarios, pero también podría haber estado asociada a deficiencias nutricionales (Rajeshkumar y Munuswamy, 2011), ya que estas lesiones fueron leves y escasas, pero presentes en el $95 \%$ de las muestras y muchas veces acompañada de leve infiltración de células inflamatorias.

En el intestino, las lesiones como hiperplasia de los enterocitos y de las células productoras de mucus puede estar asociada a un periodo de ayuno prolongado o una situación de estrés (como la captura y traslado), generándose cambios en la permeabilidad intestinal (Farhadi et al., 2003; Lambert, 2003). Asimismo, Magi et al. (2009) demostraron que Pseudomona anguillisepticum causaba hiperplasia de los enterocitos, infiltración de células inflamatorias, necrosis y desprendimiento de la mucosa.

No se disponen de muchos estudios acerca de lesiones en el estómago de peces. Las lesiones encontradas de hiperplasia, desprendimiento y necrosis de células epiteliales, y atrofia podrían estar explicadas por el efecto de contaminantes en el río Amazonas, el cual tiene altas cargas de materia orgánica y diversos tipos de desechos tóxicos, los cuales pueden afectar la mucosa gástrica, tal y como lo indica Haloi et al. (2013) en un estudio sobre cambios patológicos en el estómago de Chana Punctatus. Por otro lado, la degeneración grasa del hígado está asociada, tanto a dietas ricas en grasas (Reyna, 1993), como 
Cuadro 1. Frecuencia de alteraciones histológicas de las branquias, según el tipo de trastorn y su grado de afección en el 'tetra bleeding heart' (Hyphessobrycon erythrostigma procedente de Iquitos, Perú

\begin{tabular}{|c|c|c|c|c|c|c|}
\hline Trastorno & $\begin{array}{l}\text { Normal } \\
(n)\end{array}$ & $\begin{array}{l}\text { Escaso } \\
(\mathrm{n})\end{array}$ & $\begin{array}{l}\text { Leve } \\
\text { (n) }\end{array}$ & $\begin{array}{l}\text { Moderado } \\
\text { (n) }\end{array}$ & $\begin{array}{l}\text { Severo } \\
\text { (n) }\end{array}$ & $\begin{array}{c}\text { Total } \\
(\%)\end{array}$ \\
\hline \multicolumn{7}{|l|}{ Del crecimiento } \\
\hline $\begin{array}{l}\text { - Hiperplasia del } \\
\text { epitelio lamelar }\end{array}$ & 0 & 0 & 29 & 31 & 0 & 100.0 \\
\hline - Fusión de lamelas & 0 & 0 & 28 & 28 & 0 & 100.0 \\
\hline $\begin{array}{l}\text { - Atrofia de los } \\
\text { filamentos }\end{array}$ & 53 & 0 & 4 & 3 & 0 & 11.6 \\
\hline \multicolumn{7}{|l|}{ Parasitarios } \\
\hline $\begin{array}{l}\text { - Esporas de } \\
\text { Mixosporidium sp }\end{array}$ & 0 & 0 & 27 & 33 & 0 & 100.0 \\
\hline \multicolumn{7}{|l|}{ Circulatorios } \\
\hline - Edema perilamelar & 27 & 4 & 19 & 10 & 0 & 55.0 \\
\hline - Congestión lamelar & 43 & 0 & 13 & 4 & 0 & 28.3 \\
\hline \multicolumn{7}{|l|}{ Inflamatorios } \\
\hline $\begin{array}{l}\text { - Infiltración de } \\
\text { células inflamatorias }\end{array}$ & 22 & 2 & 24 & 12 & 0 & 63.3 \\
\hline
\end{tabular}

Cuadro 2. Frecuencia de alteraciones histológicas en hígado, según el tipo de trastorno y su grado de afección, en el 'tetra bleeding heart' (Hyphessobrycon erythrostigma), procedente de Iquitos, Perú

\begin{tabular}{|c|c|c|c|c|c|c|}
\hline Trastorno & $\begin{array}{l}\text { Normal } \\
(\mathrm{n})\end{array}$ & $\begin{array}{l}\text { Escaso } \\
\text { (n) }\end{array}$ & $\begin{array}{l}\text { Leve } \\
\text { (n) }\end{array}$ & $\begin{array}{l}\text { Moderado } \\
\text { (n) }\end{array}$ & $\begin{array}{l}\text { Severo } \\
\text { (n) }\end{array}$ & $\begin{array}{c}\text { Total } \\
(\%)\end{array}$ \\
\hline \multicolumn{7}{|l|}{ Circulatorios } \\
\hline - Congestión hepática & 39 & 0 & 14 & 7 & 0 & 35.0 \\
\hline \multicolumn{7}{|l|}{ Inflamatorios } \\
\hline $\begin{array}{l}\text { - Granuloma } \\
\text { parasitario }\end{array}$ & 40 & 11 & 9 & 1 & 0 & 33.3 \\
\hline $\begin{array}{l}\text { - Granuloma } \\
\text { bacteriano }\end{array}$ & 56 & 4 & 0 & 0 & 0 & 6.6 \\
\hline $\begin{array}{l}\text { - Infiltración de } \\
\text { células inflamatorias }\end{array}$ & 48 & 0 & 12 & 0 & 0 & 20.0 \\
\hline \multicolumn{7}{|l|}{ Degenerativos } \\
\hline $\begin{array}{l}\text { - Degeneración } \\
\text { hidrópica }\end{array}$ & 7 & 1 & 2 & 21 & 29 & 88.3 \\
\hline - Degeneración grasa & 34 & 0 & 10 & 11 & 5 & 43.3 \\
\hline $\begin{array}{l}\text { - Necrosis de los } \\
\text { hepatocitos }\end{array}$ & 50 & 2 & 7 & 1 & 0 & 16.6 \\
\hline
\end{tabular}


Cuadro 3. Frecuencia de alteraciones histológicas en riñón, según el tipo de trastorno y su grado de afección, en el 'tetra bleeding heart' (Hyphessobrycon erythrostigma) procedente de Iquitos, Perú

\begin{tabular}{|c|c|c|c|c|c|c|}
\hline Trastorno & $\begin{array}{l}\text { Normal } \\
(\mathrm{n})\end{array}$ & $\begin{array}{l}\text { Escaso } \\
(\mathrm{n})\end{array}$ & $\begin{array}{l}\text { Leve } \\
\text { (n) }\end{array}$ & $\begin{array}{l}\text { Moderado } \\
\text { (n) }\end{array}$ & $\begin{array}{l}\text { Severo } \\
(\mathrm{n})\end{array}$ & $\begin{array}{c}\text { Total } \\
(\%)\end{array}$ \\
\hline \multicolumn{7}{|l|}{ Del crecimiento } \\
\hline $\begin{array}{l}\text { - Atrofia de los } \\
\text { túbulos renales }\end{array}$ & 59 & 1 & 0 & 0 & 0 & 1.6 \\
\hline \multicolumn{7}{|l|}{ Circulatorios } \\
\hline - Edema peritubular & 23 & 35 & 2 & 0 & 0 & 61.6 \\
\hline \multicolumn{7}{|l|}{ Inflamatorios } \\
\hline $\begin{array}{l}\text { - Granuloma } \\
\text { bacteriano }\end{array}$ & 25 & 8 & 0 & 0 & 0 & 13.3 \\
\hline $\begin{array}{l}\text { - Infiltración de } \\
\text { células inflamatorias }\end{array}$ & 52 & 7 & 0 & 1 & 0 & 13.3 \\
\hline \multicolumn{7}{|l|}{ Degenerativos } \\
\hline $\begin{array}{l}\text { - Degeneración } \\
\text { hidrópica }\end{array}$ & 4 & 0 & 16 & 33 & 7 & 93.3 \\
\hline $\begin{array}{r}\text { - Necrosis de los } \\
\text { túbulos renales }\end{array}$ & 46 & 13 & 0 & 1 & 0 & 23.3 \\
\hline
\end{tabular}

Cuadro 4. Frecuencia de alteraciones histológicas en intestinos, según el tipo de trastorno y su grado de afección, en el 'tetra bleeding heart' (Hyphessobrycon erythrostigma) procedente de Iquitos, Perú

\begin{tabular}{lcccccc}
\hline Trastorno & $\begin{array}{c}\text { Normal } \\
(\mathrm{n})\end{array}$ & $\begin{array}{c}\text { Escaso } \\
(\mathrm{n})\end{array}$ & $\begin{array}{c}\text { Leve } \\
(\mathrm{n})\end{array}$ & $\begin{array}{c}\text { Moderado } \\
(\mathrm{n})\end{array}$ & $\begin{array}{c}\text { Severo } \\
(\mathrm{n})\end{array}$ & $\begin{array}{c}\text { Total } \\
(\%)\end{array}$ \\
\hline $\begin{array}{l}\text { Del crecimiento } \\
-\begin{array}{l}\text { Hiperplasia de las } \\
\text { células epiteliales }\end{array}\end{array}$ & 13 & 2 & 24 & 17 & 4 & 78.3 \\
$\begin{array}{l}- \text { Hiperplasia de las } \\
\text { células productoras } \\
\text { de mucus }\end{array}$ & 53 & 0 & 6 & 1 & 0 & 11.6 \\
$-\begin{array}{l}\text { Atrofia de las células } \\
\text { epiteliales }\end{array}$ & 58 & 1 & 1 & 0 & 0 & 3.3 \\
$\begin{array}{l}\text { Inflamatorios } \\
- \text { Infiltración de } \\
\text { células inflamatorias }\end{array}$ & 53 & 3 & 4 & 0 & 0 & 11.6 \\
$\begin{array}{l}\text { Degenerativos } \\
- \text { Degeneración } \\
\text { hidrópica }\end{array}$ & 54 & 0 & 5 & 1 & 0 & 8.3 \\
$-\begin{array}{l}\text { Desprendimiento de } \\
\text { las células epiteliales }\end{array}$ & 48 & 9 & 3 & 0 & 0 & 20.0 \\
$-\begin{array}{l}\text { Necrosis de los } \\
\text { enterocitos }\end{array}$ & 35 & 6 & 10 & 9 & 0 & 41.6 \\
\hline
\end{tabular}



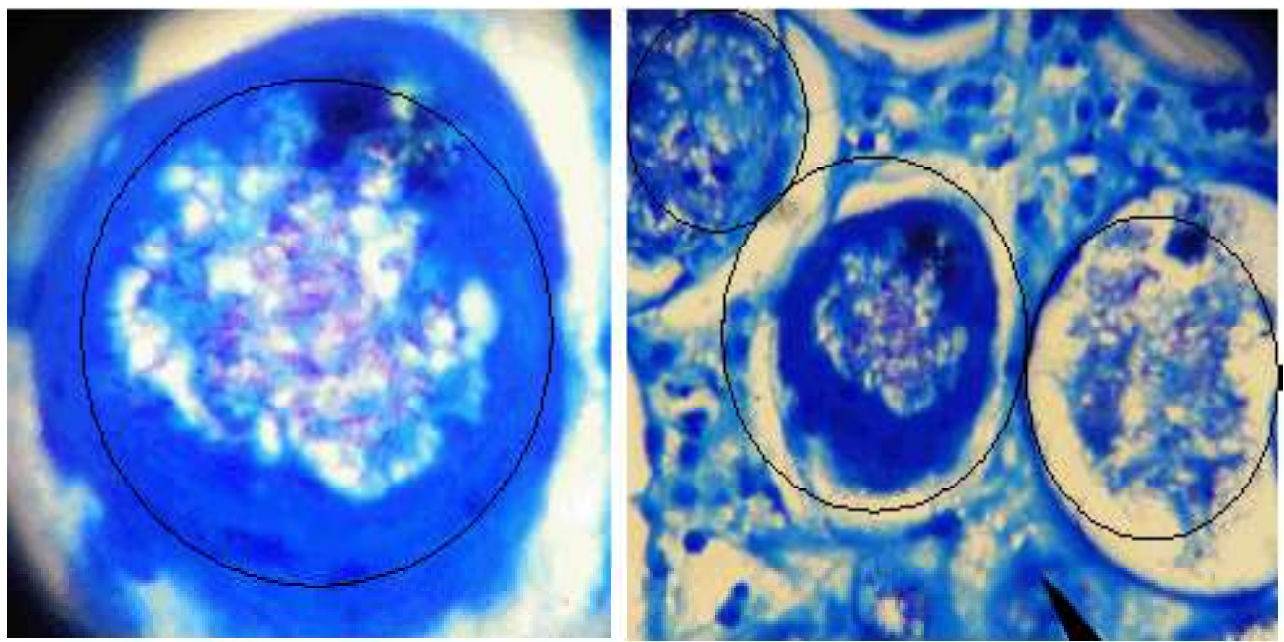

Figura 4. Granulomas bacterianos positivos a Ziehl Neelsen. Obsérvese bacterias bacilares ácido-resistentes en el interior de los granulomas (círculo). 1000X

a una movilización rápida de las reservas lipídicas por ayunos prolongados (Vigliano et al., 2002).

Con respecto a las lesiones encontradas en el riñón, tales como degeneración hidrópica, edema peritubular y necrosis de los túbulos renales, Fathy et al. (2013), en su estudio en Poecilia reticulata y Gambusia affinis expuestos al bisfenol A (compuesto orgánico empleado en la fabricación de plásticos) indican que este tipo de lesiones están relacionadas a causas no infecciosas.

Granulomas bacterianos similares a los encontrados en el presente estudio en hígado, riñón, músculo esquelético, bazo y peritoneo han sido descritos por Huang et al. (1999) en tilapias infectadas con Staphylococcus epidermidis, demostrando que bacterias del género Staphylococcus producen granulomas de manera sistémica. Asimismo, diversas bacterias del género Mycobacterium inducen enfermedad sistémica crónica con formación de granulomas en órganos de peces (Frerichs, 1989). Las más comunes en peces de acuario y en el medio natural son M. marinum, M. fortuitum y $M$. chelonae
(Roberts, 2001), aunque también pueden encontrase $M$. abscessus, $M$. neoaurum, $M$. scrofulaceum y $M$. siniae; todas ellas con capacidad de infectar al humano (Rhodes et al., 2001). Verján et al. (2002) reportaron infecciones por Mycobacterium sp con presencia de granulomas en tejidos parenquimatosos y conectivos en siete especies de peces ornamentales (escalar [Ptero-phyllum altum], cardenal [Parachei-rodon axelrodi], disco [Symphysodon aequifas-ciata], betta [Betta splendens], goldfish [Carassius auratus] y gourami [Trichogaster trichopterus]).

\section{Conclusiones}

- Se aislaron siete agentes bacterianos en peces 'tetra bleeding heart', pertenecientes a los géneros Flavobacterium, Lactobacillus, Pseudomonas, Aeromonas, Bacillus, Stpahylococcus y Escherichia.

- De las 42 muestras con granulomas bacterianos encontrados en peritoneo, riñón, bazo, hígado y músculo esquelético, 22 de ellas fueron positivos a la tinción 
de Ziehl Neelsen, donde se evidenciaron bacterias bacilares largas acidorresistentes.

- Se identificaron agentes parasitarios como los protozoos Mixosporidium sp en branquias y Microsporodim sp en músculo, así como granulomas parasitarios en peritoneo e hígado.

- Se encontraron diversos hallazgos histopatológicos en branquias, hígado, riñón, bazo, músculo esquelético, peritoneo, intestino delgado y piel.

\section{Agradecimientos}

Los autores manifiestan su agradecimiento al Vicerrectorado de Investigación de la Universidad Nacional Mayor de San Marcos por el financiamiento del estudio.

\section{Literatura Citada}

1. Araujo A, Bances K. 2009. Actualización de información de la cadena productiva de peces ornamentales. Iquitos, Perú: Centro de Promoción de la Biodiversidad Amazónica. Instituto de Investigaciones de la Amazonía Peruana - IIAP. 24 p.

2. Austin B, Austin D. 2007. Bacterial fish pathogens. Diseases of farmed and wild fish. $4^{\text {th }}$ ed. Germany: Chichester. $575 \mathrm{p}$.

3. Bland JM, Altman DG. 1986. Statistical methods for assessing agreement between two methods of clinical measurement. Lancet 327: 307310. doi: 10.1016/S0140-6736(86)90837-8

4. Carvalho E, Belém-Costa A, Porto J. 2015. Identificação bioquímica de bactérias patogênicas isoladas de peixes ornamentais no estado do Amazonas. Rev Bras Saúde Prod Anim 16: 170-178. doi: 10.1590/S1519-99402015000100018

5. [CFSPH] The Center for Food Security and Public Health. 2007. Micobacteriosis. The Center for Food Security and Public Health. Aquatic Animal Disease 8: 1-4. Available in: http://
www.cfsph.iastate.edu/Factsheets/pdfs/ mycobacterium_marinum.pdf

6. Chuquipiondo C. 2014. Profilaxis y sanidad en peces ornamentales. Iquitos: Stingray Aquarium. $38 \mathrm{p}$

7. Domitrovic HA. 1998. Histopatología branquial en Aequidens portalegrensis (Hensel, 1870): II. Lesiones parasitarias. Rev Ictiología 6(1/12): 43-55.

8. Ellis AE. 2001. Innate host defense mechanisms of fish against viruses and bacteria. Dev Comp Immunol 25: 827-839. doi: 10.1016/S0145-305X(01)00038-6

9. [FAO] Food and Agriculture Organization of the United Nations. 2010. Visión general del sector pesquero nacional. Lima, Perú: FAO. Informe técnico. 24 p. [Internet]. Disponible en: ftp:/ /ftp.fao.org/Fi/document/fcp/es/ FI_CP_PE.pdf

10. Farhadi A, Banan A, Fields J, Keshavarzian $J$. 2003. Intestinal barrier: an interface between health and disease. J Gastroenterol Hepatol 18: 479497. doi: 10.1046/j.1440-1746.2003.03032.x

11. Fathy M, Walid A, Sayed A. 2013. Histopathological changes in the kidney of mosquito fish, Gambusia affinis and guppy fish, Poecelia reticulata exposed to Bisphenol. Egypt J Aquat Biol Fish 17: 83-93. doi: 10.21608/ejabf.2013.2188

12. Ferguson $\boldsymbol{H W}$. 2006. Systemic pathology of fish. $2^{\text {nd }} e d$. London: Scotian Press. $366 \mathrm{p}$.

13. Frerichs GN. 1989. Bacterial diseases of marine fish. Vet Rec 125: 315-318.

14. Haloi K, Kalita M, Nath R. 2013. The study on the histopathological changes of stomach of Channa puncatatus (Block) by used pesticide endosulfan. Global J Sci 13: 1-7.

15. Holt J, Krieg N, Sneath P, Staley J, Williams S. 2000. Bergey's manual of determinative bacteriology. $9^{\text {th }}$ ed. Philadelphia, USA: Lippincott Williams \& Wilkins. $799 \mathrm{p}$.

16. Huang S, Chen W, Shei M, Liao I, Chen S. 1999. Studies on epizootiology and pathogenicity of Staphylococcus 
epidermidis in tilapia (Oreochromis spp) cultured in Taiwan. Zoological Studies 38: 178-188.

17. Iregui A, Eslava P, Martínez E, Figueroa J. 1999. Descripción de un caso de mixosporidiasis clínica en cachama blanca (Piaractus brachypomus). Dahlia 3: 17-29.

18. Lambert G. 2003. Stress-induced gastrointestinal barrier dysfunction and its inflammatory effects. J Anim Sci 87(Suppl 14): E101-E108. doi: 10.2527/ jas.2008-1339

19. Magi GE, Lopez S, Magariños GE, Lamas J, Toranzo AE, Romalde L. 2009. Experimental Pseudomonas angui-llisepticum infection in turbot Psetta maxima: a histopathological and immunohistochemical study. Eur J Histochem 53(2): e9. doi: 10.4081/ ejh.2009.e9

20. Mohamed E, Mohamed M. 2008. Bacterial causes of skin ulcers affection in Tilapia nilotica (Oreochromis niloticus) with especial reference to its control. VIII International Symposium on Tilapia in Aquaculture. El Cairo, Egypt.

21. Noga J. 2000. Fish disease. Diagnosis and treatment. USA: Iowa State University Press. $497 \mathrm{p}$.

22. Orvay F. 1993. Acuicultura marina: fundamentos biológicos y tecnología de la producción. España: Ed Universitat Barcelona. $739 \mathrm{p}$.

23. Palacios S, Sandoval N, Bueno C, Manchego A. 2015. Estudio microbiológico e histopatológico en peces neón tetra (Paracheirodon innesi) de la Amazonia Peruana. Rev Inv Vet Perú 26: 469-483. doi: 10.15381/rivep.v26i3.11176

24. Rajeshkumar S, Munuswamy $N$. 2011. Impact of metal on histopathology anda expression of HSP 70 in different tissues of milk fish (Chamos chanos) of Kaattuppalli Island, South East Coast, India. Chemosphere 83: 415-421. doi: 10.1016/j.chemosphere.2010.12.086
25. Ramírez W, Rondón I, Vidal H, Eslava P. 2009. Toxicidad agua y lesiones histopatológicas en cachama blanca (Piaractus brachypomus) expuestas a la mezcla de herbicida Roundoup ${ }^{\circledR}$ más surfactante Cosmoflux ${ }^{\circledR}$ 411F. Rev MVZ Córdova 14: 1563-1575.

26. Reimschuessel R, May E, Bennett R, Lypsky M. 1988. Necropsy examination of fish. Vet Clin N Am-Small 18: 427433. doi: 10.1016/S0195-5616(88)50040-2

27. Reimschuessel R, May E, Bennett R, Lypsky M. 1992. A classification system for histological lesions. J Aquat Anim Health 4: 135:143. doi: 10.1577/ $1548-8667$ (1992) $004<0135$ :CACSFH $>2.3 . \mathrm{CO} ; 2$

28. Reyna S. 1993. Patología celular y tisular. En: Trigo F, Poumián A (eds). Patología general veterinaria. México: Nueva Ed Interamericana. p 26-30.

29. Rhodes MW, Kator H, Kotob S, van Berkum PV, Kaattari I, Vogelbein W, Floyd MM, et al. 2001. A unique Mycobacterium species isolated from an epizootic of striped bass (Morone saxatilis). Emerg Infect Dis 7: 896- 899. doi: 10.3201/eid0705.017523

30. Roberts J, Shepherd J. 1980. Enfermedades de la trucha y el salmón. España: Acribia. $187 \mathrm{p}$.

31. Roberts R. 2001. Fish patology. $3^{\text {rd }}$ ed. Edinburgh: WB Saunders. 472 p.

32. Ross L, Ross B. 2008. Anaesthetic and sedative techniques for aquatic animals. $3^{\text {rd }}$ ed. Scotland, UK: Blackwell Publishing. $222 \mathrm{p}$.

33. Rosenthal S, Sandoval N, Gavidia C, Tabacchi L. 2013. Frecuencia de lipidosis hepática en truchas arcoíris (Oncorhynchus mykiss) de fase juvenil en una piscigranja de la sierra central del Perú. Rev Inv Vet Peru 24: 118-124. doi: 10.15381/rivep.v24i1.1675

34. Ruíz G 2005. Estudio de la cadena productiva de peces ornamentales provenientes de la región Loreto en el Perú. Iquitos, Perú: Instituto de Investigaciones de la Amazonía Peruana - IIAP. 91 p. 
35. Salcido M. 1998. Enfermedades bacterianas en sistemas de producción de peces. Tesis de Químico Biólogo. Sonora, México: Univ. de Sonora. $116 \mathrm{p}$.

36. Trust T, Bull L, Currie B, Buckley J. 1979. Obligate anaerobic bacteria in the gastrointestinal microflora of the grass carp (Ctenopharyngodon idella), goldfish (Carassius auratus), and rainbow trout (Salmo gairdneri). J Fish Res Board Can 36: 1174-1179. doi: 10.1139/f79-169
37. Verján N. 2002. Sistematización y caracterización de las enfermedades de la cachama blanca (Piaractus brachypomus) en algunas regiones de los Llanos Orientales y estudio de la enfermedad septicémica. Tesis de Maestría. Bogotá: Univ Nacional de Colombia. $120 \mathrm{p}$.

38. Vigliano F, Quiroga M, Nieto J. 2002. Adaptaciones metabólicas y realimentación en peces. Rev Ictiol 10: 79-108. 